\title{
THE LEARNING ORGANISATION: VALIDATING A MEASURING INSTRUMENT
}

De Villiers, WA

University of Pretoria, South Africa

\begin{abstract}
The EFMD reports in their Survey Summary Service (2006) that "The Learning Organization" topic ranked as the second most enduring idea about strategy and business, out of 10 ideas most likely to last at least another 10 years. Management literature contains a considerable number of references to the learning organization and its characteristics. An instrument developed by Pedler, et. al. (1991) to measure eleven characteristics of the learning organization was used to measure the degree to which respondents considered their own organizations to conform to the eleven characteristics ascribed to the learning organization. The aim of this paper is to report on the research and analyses being done to better understand the factor structure and content of the construct, as well as the predictive and discriminate validity of the same instrument. Item Analysis, Exploratory Factor Analysis and Confirmatory Factor Analysis were used for this purpose. The predictive/discriminatory validity of the instrument, which has been proved to be uni-dimensional, was investigated by means of One-way Analysis of Variance, Stepwise Discrimination Analysis and Discrimination Analysis. The results indicate that the instrument can adequately distinguish respondents from different economic sectors and organizations as well as differentiate respondents in terms of some other variables. The study should be regarded as entirely applicable to the South African cultural and organizational environments.
\end{abstract}

\section{INTRODUCTION}

The phenomenon known as the learning organizations has during the past two decades been discussed widely in the literature (Hawkins, 1991; Watkins \& Marsick, 1993; Senge, 1990; Pedler, Burgoyne \& Boydell, 1991). It seems as if it can be argued that during the 1970s and 1980s strategy and organizational efficiency were emphasized. Recently Hawkins (in Burgoyne, Pedler \& Boydell, 1994) emphasized the need for the soul of an organization to be activated and integrated with its operational and strategic functioning. This ties in with the views of Pedler, et al. (1991) who felt that the learning organization dream is for people who believe that there is a massive locked up, hidden, underdeveloped potential in organizations and who want to unlock, release and develop this potential. Davis (in Burgoyne, et al., 1994:57) seems to agree with this when he concludes: "We may need to find organizational forms in which the structure can embody the spirit and the spirit internalize the structure and in which both continually change". Reasons why learning organizations are needed are often seen in the literature. The need for organizations to learn and develop in order not to die, seems to be a popular idea (Kast \& Rozensweig, 1985; Robinson, 1994; Senge, 1990). Continues improvement of your product/service is so vital in today's marketplace, organizations need to learn faster and smarter just to stay in the same place (DiBella and Nevis, 1998). The saying goes: If you think learning is expensive, try ignorance.

Pedler, et al. (1991) developed an instrument to measure, what they called, "the eleven characteristics of a learning company." This instrument is used to determine where the organization currently is on its way to become a fully fledged learning organization. Too little is known about what is being measured by this questionnaire. This study is therefore an attempt to determine the underlying dimensions measured by the instrument and to learn more about the portability or not, of the construct embodied in the instrument. In this way it was hoped to contribute towards a better understanding of what the whole notion of the learning organization entails.

Research of the factor structure and content of the learning organization construct was done. Results shown that the construct as measured by Pedler, Burgoyne \& Boydell's (1991) eleven characteristics questionnaire seems to be uni-dimensional. Then the predictive/discriminatory validity of the instrument, which has been proved to be uni-dimensional, was investigated by means of One-way Analysis of Variarance. The results indicate that the instrument can adequately distinguish respondents from different economic sectors and organizations as well as differentiate respondents in terms of some other variables.

\section{THEORETICAL BACKGROUND}

Pedler, et al. (1991:1) define a learning organization as 
".... an organization that facilitates the learning of all its members and continuously transforms itself". Watkins \& Marsick (1993:83) elaborate on the concept when they describe the learning organization as ".... One that learns continuously and transforms itself. Learning takes place in individuals, teams, the organization, and even the communities with which the organization interacts. Learning is a continuous, strategically used process integrated with, and running parallel to, work. Learning results in changes in knowledge, beliefs and behaviors. Learning also enhances organizational capacity for innovation and growth. The learning organization has embedded systems to capture and share learning". There have been so many conceptions of the learning organization by different authors including several foci (Watkins \& Golembiewski, 1995). Consensus on the contents of the concept does not seem to exist, although there is lots of common ground amongst researchers. From a scientific as well as a practical viewpoint, it seems to be necessary to clarify the concept as soon as possible in order to use the construct consistently and with confidence. For this to happen reliable and valid measurement of the construct must be possible.

Revans (1982) formulated the notion that for an organization to survive, its rate of learning must be equal to, or greater than, the rate of change in its external environment. To achieve this, the concept to the learning organization and the importance of this type of approach was emphasized by Senge (1990). Some of the key influences making it necessary to move towards the learning organization have been identified as: The need to achieve high and uniform levels of quality; rapid and continuous changes in technology; the need for a service orientation; global turmoil and competition; the world becoming a global village; the entry into the organization of knowledge workers in large numbers, and coping with increasing uncertainty in a global market (Bahlman, 1990; Donegan, 1990; Hall, 1990; Jones \& Hendry, 1992; Mohrman, Mohrman, Ledford, Cummings \& Lawler, 1989; Senge, 1990; Walker, 1992; Watkins, et al., 1993). Unless organisations continuously develop their capacity and capability to learn, they are doomed to suffer from such adverse tendencies like market myopia, groupthink, reinventing the wheel and repeating the same mistakes (DiBella and Nevis, 1998).

It seems as if it can be argued that an organization's ability to learn faster than its competitors, may be in future the only sustainable competitive advantage (De Geus, 1988; Donegan, 1990; Schein, 1993; Senge, 1990; State 1989; Walker, 1992).

Unless they can become learning organizations, they will not survive to do business in this millennium (Senge, 1990). What, how, when, how smart and how fast an organization learns has everything to do with its ability to compete.

On how to precisely define a learning organization, Swieringa \& Wierdsma (1992:72) concluded: "We do not know what learning organizations precisely look like." Some attempts have, however, been made to define the characteristics and nature of such an organization (Banner, 1987; Gharajedaghi \& Ackoff, 1984; Senge, 1990; Garratt, 1987; Gharajedaghi \& Ackoff, 1984; Senge, 1990; Garratt, 1987; Kochan \& Useem, 1992; Pedler, et al., 1991). Watkins \& Marsick (1993:8) seem to include most of the elements of the definitions into their statement: "The learning organization is one that learns continuously and transforms itself. Learning takes place in individuals, teams, the organization, and even the communities with which the organization interacts. Learning is a continuous, strategically used process integrated with, and running parallel to work. Learning results in changes in knowledge, beliefs and behaviors. Learning also enhances organizational capacity for innovation and growth. The learning organization has embedded systems to capture and share learning".Yeo (2005) found in his research that the synthesis of the literature reveals several common themes from various learning organization definitions. He clearly differentiate between the term "organizational learning" to refer to the process of learning, while "learning organization" refers to a type of organization rather than a process (Yeo, 2003). Gorelick (2005) concluded that organizational learning and the learning organization can and should co-exist.

Literature today is overwhelmed by authors presenting the learning organization approach as the new challenge for managers in an increasingly turbulent global business environment. The question remains, is the learning approach an effective practical way for providing guidance to organizations into the future? The learning organization approach to management has generated considerable interest in recent years among both scholars and practitioners. In fact, Nevis, DiBella \& Gould (1995) conclude from their studies on organizations, that all organizations are learning systems. But according to them learning conforms to culture, style varies between learning systems and generic processes facilitate learning (Nevis, et al, 1995:75). Dibella and Nevis (1998, p4) argued that it is 'a matter of perspective'. They clustered the orientations of selected authors into three perspectives namely: 1) The normative perspective - organizational learning takes place under a unique set of conditions, a specific type 
of organization with specific characteristics (The Learning Organization: A Matter of Becoming); 2) The developmental perspective - learning organization represents a late stage of organizational development; 3) The capability perspective - learning is innate to all organizations (The Learning Organization: A Matter of Being). They then compare features like time orientation, source, learning style, relationship between learning and culture, and management focal point to indicate the differences between the three perspectives (DiBella and Nevis, 1998, p7-18). DiBella (2001) developed also the so called "Organizational Learning Inventory" tool, used to profile a team's or organization's learning capability.

When we do research, we seek to know "what is" in order to understand, explain, and predict phenomena. When dealing with a question like, what is a learning organization, the use of concepts, constructs and definitions are required (Emory \& Cooper, 1991). Scientific methods and thinking are based on concepts. A concept is a bundle of meanings or characteristics associated with certain events, objects, conditions, or situations. Concepts are created by classifying and categorizing objects or events that have common characteristics beyond the single observation. In research we often run into difficulty with newly advanced concepts. Abstract concepts are called constructs. A construct is an invented name for a property (Kerlinger, 1986; Anastase, 1986). Concepts and constructs must be defined operationally in order to measure the properties of a construct. This is done by specifying the indicants of the properties (Emory \& Cooper, 1991; Kerlinger, 1986).

"Measurement is the assignment of numerals to objects or events according to rules". (Kerlinger, 1986:392). Evidently measurement is a relation, a relation is a function and therefore all measurement procedures are functions (Kerlinger, 1986:393). It is said that the measurement procedure and the number system are isomorphic to reality. Isomorphism means identify or similarity of form. In measurement the question is: Do the measurement procedures being used have some national and empirical correspondence with reality? Or, are the sets of objects the same or similar in some formal aspect? Obviously the ultimate question to be asked of any measurement procedure is: Is the measurement procedure isomorphic to reality? Kerlinger (1986:396) said we actually measure indicants of the characteristics of objects. Indicant means something that points to something else. So some identifiable behavior of an organization is an indicant of an underlying characteristic.
To the extent that measurement is reliable and valid, to that extent one will have faith in using that result consistently and with confidence in practice. This paper reports on the discriminate validity of the eleven characteristic question of Pedler, et al. (1991). Reliability is about the stability and accuracy of the instrument. Validity is about what is being measured; are we measuring what we think we are measuring? Three types of validity are identified: content, criterion related, and construct. Content validity is about the respresentativeness, or sampling adequacy of the content. Criterion related validity is more about the predictive ability of the instrument. With construct validity we wish to know the meaning of the test. We seek to explain individual differences in test scores. The properties being measured are more important than the test used for measuring. The significant point about construct validity is its preoccupation with theoretical constructs and scientific empirical inquiry involving the testing of hypothesized relations. In the last case, convergence and discriminability are required. Convergence means that evidence from different sources gathered in different ways all indicates the same meaning of the construct. Discriminability means that one can empirically differentiate amongst constructs that may be similar (Kerlinger, 1986:421; Anastasi, 1986:4).

Anastasi (1986:3) postulates that the development of a valid test requires multiple procedures which are sequentially built into the test from the outset of construction. Anastasi (1986:12) summarized these processes very elegantly when she said:

"So-called content validation and criterion related validation can be more appropriately regarded as stages in the construct validation of all tests. There is a growing recognition that validation extends across the entire test construction process; it encompasses multiple procedures employed sequentially through internal and external statistical analyses of empirical data. Depending upon the purpose of the test, trait constructs may be defined with different degrees of narrowness or breadth and may be linked to specified situational domains. The identification of constructs in both test performance and criterion behavior increases the efficiency of the test construction process and leads to the production of tests that are more valid theoretically, as well as more useful in meeting practical needs." Almost any information gathered in the process of developing or using a test is relevant to its validity, in the sense that it contributes to our understanding of what the test measures. Construct validation is indeed a never ending process. 


\section{METHOD}

\section{Participating Organizations}

The largest group of respondents came from 30 different organizations. These organizations functioned in different economic sectors and sub sectors viz. Agriculture (3 organizations, 48 respondents); Mining (3:35); Manufacturing (4:81); Electricity and Gas (2:63); Construction (2:22); Wholesale and Retail (5:44); Transport, Storage, Communication (3:56); Financial and Insurance (3:62); Community and Social Services (4:81).

A second grouping of respondents were individuals who voluntarily completed the questionnaire while attending a Management Development Programme $(\mathrm{N}=124)$, Marketing Management Course ( $\mathrm{N}=22)$ and a Logistics Management short course $(\mathrm{N}=19)$ at the Graduate School of Management of the University of Pretoria. In contrast with all the other respondents, the 124 students on the MDP have been exposed to some 2 hours lecturing on the theory of the learning organization. In total 657 respondents therefore provided usable questionnaires.

\section{Measuring Instrument}

The questionnaire used, had been developed by Pedler, et al. (1991). It consists of 110 items which are arranged under 11 scales i.e. the characteristics which are supposed to typify the learning organization. Respondents were asked to react on a 7 point scale, where $1=$ not at all like this and $7=$ a lot like this. According to the authors, the eleven characteristics can be grouped into 5 clusters. The structures of variables which the instrument is supposed to measure are shown in Figure 1.

\section{Procedure}

Contact persons (agents) were arranged in each of the 30 organizations from which respondents had to be drawn. Questionnaires were given to the agents for distribution in the organizations of which they were members. The number of questionnaires handed to each agent was roughly proportional to the number of employees in the organization. The agents were asked to distribute these questionnaires to potential respondents in proportion to the distribution of employees in the organization over hierarchical levels, functional groups, sex, age, home language and racial groupings.

Figure 1 : Structure Of The Eleven Characteristics Questionnaire

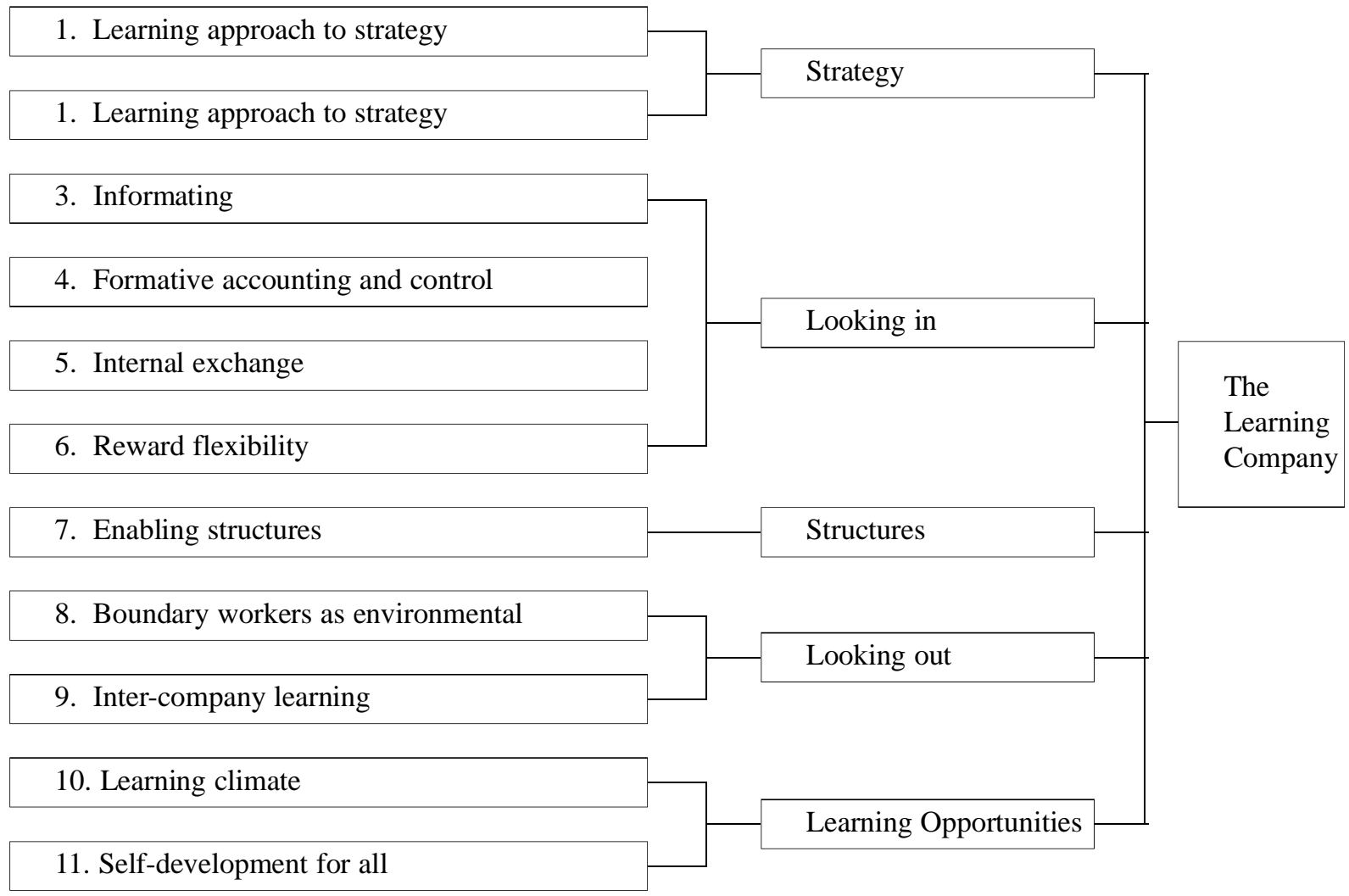

Source: Pedler, et al., 1991: 25 
Agents were also asked not to distribute the questionnaire to the lowest level of employees or to top managers in their organizations. A deadline of one month after the distribution of the questionnaires was specified as the return date. Emphasis was placed on the voluntary completion of the questionnaires. The questionnaires were also personally handed to another 205 individuals attending short courses at the Graduate School of Management. The overall return rate of questionnaires was $66.1 \%$. Of questionnaires distributed through agents in organizations $62.4 \%$ were returned and usable. The corresponding figure for questionnaires distributed to participants in short courses was $80.4 \%$. In total 657 questionnaires could be used in the analysis. Principals Components Analysis, utilizing the Statistical Analysis System on the computer system of the University of Pretoria, followed by Item Analysis were used to determine the underlying dimensions of the variables measured by The Eleven Characteristics of the Learning Organization Questionnaire.

\section{FINDINGS}

The purpose of the data analysis was firstly to determine the homogeneity of the items in the questionnaire as well as the underlying dimension(s) measured by the instrument. An attempt was therefore made to determine whether the "original" factor structure as defined by Pedler, et al. (1991) would be replicated by the findings of the responses gathered during the present study.

The first step of the analysis was to do a Principal Components factor analysis on the responses of the subjects. A Scree test was included to help with the interpretation. The "How it is" responses were used for this purpose. Varimax and Promax rotations were carried out. A total of 21 eigenvalues higher than one were obtained, the highest eigenvalue being 39.99 and the second highest 3.11. This large "distance" between the two highest eigenvalues created a suspicion that the items would possibly group into one underlying dimension. An 11-factor solution was, however, tried in order to see whether the structure as formulated by Pedler, et al. (1991) could be replicated. A Varimax rotation rendered eleven factors, with the highest loadings on factors one to eleven shown in Table 1. All the highest loadings were above .30. These 11 factors together explained $49.25 \%$ of the total variance. They respectively (rounded off) explained between 28.9 and $2.9 \%$ of the common variance (see Table 1) and between 31.8 and $1.2 \%$ of the total variance. The relatively small proportions of variance explained by the last 10 factors seemed to point to a lower number of factors being an optimum solution. There were also a large number of items which loaded on more than one factor. The large percentage of the total variance explained by the first factor $(31.8 \%$ ) against the $2.9 \%$ explained by the second factor seemed to point to the probability that the construct is measured by the instrument used in this study was possibly uni-dimensional. As it was regarded as possible that the dimensions measured by the instrument would not be independent from each other a Promax rotation was also carried out again, extracting 11 factors. This yielded a factor pattern in which between 46 and 1 item loaded respectively on the 11 factors. The pattern of factor loadings was nearly the same as after Varimax rotation. The 11 factors now explained between 52.9 and $2.8 \%$ of the common variance. (see also Table 1).

Table 1: Loadings on Factors in Varimax and Promax Rotations with \% Explanation of Common Variance

\begin{tabular}{|l|c|c|c|c|}
\hline \multicolumn{3}{|c|}{ VARIMAX ROTATION } & \multicolumn{2}{c|}{ PROMAX ROTATION } \\
\hline FACTORS & $\begin{array}{c}\text { NUMBER } \\
\text { OF ITEMS }\end{array}$ & $\begin{array}{c}\text { \% COMMON } \\
\text { VARIANCE }\end{array}$ & $\begin{array}{c}\text { NUMBER } \\
\text { OF ITEMS }\end{array}$ & $\begin{array}{c}\text { \% COMMON } \\
\text { VARIANCE }\end{array}$ \\
\hline 1 & 45 & 28.9 & 46 & 52,9 \\
\hline 2 & 17 & 25.5 & 18 & 38,2 \\
\hline 3 & 11 & 10.5 & 10 & 27,9 \\
\hline 4 & 10 & 8.6 & 11 & 30,9 \\
\hline 5 & 9 & 8.4 & 8 & 18,3 \\
\hline 6 & 6 & 6.8 & 5 & 17,2 \\
\hline 7 & 5 & 5.8 & 4 & 13,0 \\
\hline 8 & $2 *$ & 5.1 & 4 & 19,9 \\
\hline 9 & 3 & 4.3 & $2 *$ & 3,9 \\
\hline 10 & $1 *$ & 3.3 & $1 *$ & 3,7 \\
\hline 11 & $1 *$ & 2.9 & $1 *$ & 2,8 \\
\hline
\end{tabular}

* It is generally accepted that a factor is constructed by 3 or more variables. Thus, this factor could easily be ignored.

Neither of the two 11-factor solutions (with Varimax or Promax rotations) replicated the 11-factor structure as proposed by Pedler, et al. (1991). The item loading pattern over the eleven factors as identified in this analysis had no resemblance to the item distribution as identified by Pedler, et al. (1991). It was, however, decided to attempt a second line of analysis i.e. item analysis to ascertain whether the items in the questionnaire were sufficiently related to each other to be regarded as contributing to the same scale. The corrected rtt-values of the items varied between .34 and .73. As all items had rtt-values of $>.30$, it was concluded that no items should be eliminated from the analyses and that all the items could be regarded as part of the same variable/scale. 
A third line of analyses was to extract only one factor - partly promoted by the results of the item analysis which indicated that all the items correlated sufficiently to be regarded as part of one scale. This yielded a factor on which all the items loaded. The lowest loading was .34 and the highest .74. This result also pointed to the construct being uni-dimensional.

To learn more about the construct second, order factor analysis (using Principal Components) was carried out. The scores on the 11 factors were used as items. A Promax rotation was specified. A one factor as well as a two factor solution was specified. This analysis yielded one eigenvalue larger than 1 i.e. 6.37 (The second highest eigenvalue was .83). The one factor solution yielded a factor pattern in which all of the eleven original factors loaded above .30 (The lowest loading was .51 and the highest .93). This one factor explained $61.2 \%$ of the total variance. The two factor solution yielded two factors which had very high cross loadings. Only one of the original factors did not have its highest loading on the first of the two second order factors and only one of the original factors did not load above .30 on both factors. The two factors explained $68.8 \%$ of the total variance and 66.7 and $33.3 \%$ respectively of the common variance.

A final step of analysis was to apply Confirmatory Factor Analysis to determine which of the two solutions provided the best fit. The results are shown in Table 2. It seems as if on most of the indices used, the one factor solution provided a better fit and this solution was therefore accepted. It seems as if it can be said, with confidence, that in the light of the evidence provided, the construct measured by the Pedler, et al. (1991) questionnaire is uni-dimensional.

It was shown that the construct as measured in the Pedlar et al. (1991) questionnaire was uni-dimension$\mathrm{al}$, that the 110 items in the questionnaire were highly related to each other i.e. the measurement had high internal validity $($ Crombach's Alpha $=.89)$. However, some doubts exist about the content validity of the instrument and further work in this regard was recommended.

Utilizing the Statistical Analysis System on the main frame computer system of the University of Pretoria, investigation of the discriminatory/predictive ability of the instrument was done by means of One-way Analysis of Variance, Stepwise Discriminant Analysis and Discriminant Analysis. Items in the questionnaire identified by means of Stepwise Discriminant Analysis as contributing significantly to distinguish-
Table 2: Results of C.F.A. on One and Two Factor Second Order Explanatory Analysis Results

\begin{tabular}{|l|c|c|}
\hline & $\begin{array}{c}\text { ONE } \\
\text { FACTOR }\end{array}$ & $\begin{array}{c}\text { TWO } \\
\text { FACTOR }\end{array}$ \\
\hline Goodness of fit Index (GFI) & .9587 & .9587 \\
\hline GFI Adjusted for df & .9366 & .9351 \\
\hline Root mean square residual & .0253 & .0253 \\
\hline Parsimonious GFI & .7495 & .7333 \\
\hline Bentler's Comparative Fit Index & .9815 & .9874 \\
\hline Akaike's Information Criterion & 57.61 & .59 .61 \\
\hline Mc Donald's Centrality & .9263 & .9256 \\
\hline Bentler \& Bonnett's Non Normed Index & .9764 & .9756 \\
\hline Bentler \& Bennett's NFI & .9739 & .9739 \\
\hline Parsimonious NFI & .7614 & .7437 \\
\hline Bollen Normed Index & .9667 & .9659 \\
\hline Bollen Non-normed Index & .9816 & .9814 \\
\hline
\end{tabular}

ing groups from each other, were used in Discriminant Analysis to "place" individual respondents in groups. This was taken as a measure of the predictive/discriminatory validity of the instrument. The respondent groups were identified under "Method". The results of the One-way Analysis of Variance which were carried out are shown in Table 3.

Table 3: Results of One-Way Analyses of Variance on Different Respondent Groups Scores

\begin{tabular}{|l|l|l|}
\hline CRITERION & $\mathrm{F}(\mathrm{df})$ & $\mathrm{p}$ \\
\hline Economic sectors & $2.01(8 ; 483)$ & $.04^{*}$ \\
\hline Organisations & $2.76(29 ; 462)$ & $.0001^{* *}$ \\
\hline Training course & $6.15(2 ; 162)$ & $.003^{* *}$ \\
\hline Exposure to concept & $2.93(1 ; 128)$ & $.09^{* *}$ \\
\hline
\end{tabular}

* Significance at 5\% level of significance ** Significance at $1 \%$ level of significance

Tukey's range test was in each case done to pinpoint differences among groups more accurately. The results indicated that pair wise comparison of groups responses yielded significant differences as indicated in Table 4.

Table 4: Significant Differences Yielded By Tukey's Ranges Tests On Group's Scores

\begin{tabular}{|l|l|}
\hline CRITERION & DIFFERENCES AND DIRECTION \\
\hline Economic sectors & $9>4$ \\
\hline Organizations & $\begin{array}{l}16>26,5,8,17,11,20,21,19,14, \\
29>11,30>11\end{array}$ \\
\hline Training courses & $\begin{array}{l}\text { Management Development }> \\
\text { Marketing Management }\end{array}$ \\
\hline
\end{tabular}

The results of the Stepwise Discriminant Analyses can be summarized as in Table 5. 
Table 5: Items Included In Stepdisc Models and Prediction Indices

\begin{tabular}{|c|c|c|c|}
\hline CRITERION & ITEMS* & LAMBDA & $\begin{array}{l}\text { ANONICAL } \\
\text { CORRELATION2 }\end{array}$ \\
\hline $\begin{array}{l}\text { Economic } \\
\text { sector }\end{array}$ & $\begin{array}{l}32,20,107,88,31 \\
5,23,70,80,26,3 \\
37,104,57,36,29 \\
94,93,47,3,8,108, \\
63,85,8,56,105\end{array}$ & .26 & .15 \\
\hline Organizations & $\begin{array}{l}32,31,42,20,91,47, \\
93,107,29,108,70, \\
3,1,88,57,53,43, \\
105,94,102,75,56, \\
9,41,7,4,58,40,24, \\
34,38,68,80,51, \\
37,36,76,74,87\end{array}$ & .007 & .15 \\
\hline $\begin{array}{l}\text { Training } \\
\text { course }\end{array}$ & $\begin{array}{l}70,73,99,77, \\
26,18,64\end{array}$ & .65 & .19 \\
\hline $\begin{array}{l}\text { Exposure } \\
\text { to concept }\end{array}$ & $\begin{array}{l}26,65,11, \\
42,93,5\end{array}$ & .66 & .34 \\
\hline
\end{tabular}

The Discriminant Analyses, using the models developed by means of the Stepwise Discriminant Analyses yielded the results in Table 6 .

Table 6: Percentages of Correct Classifications by Means of Discriminant Models

\begin{tabular}{|c|c|c|}
\hline CRITERION & $\begin{array}{l}\text { PERCENTAGE } \\
\text { "CORRECT" PER GROUP }\end{array}$ & $\begin{array}{l}\text { PERCENTAGE } \\
\text { "CORRECT" } \\
\text { TOTAL }\end{array}$ \\
\hline $\begin{array}{l}\text { Economic } \\
\text { sectors }\end{array}$ & $\begin{array}{l}1-47.9 ; 2-54.3 ; 3-54.3 \\
4-55.6 ; 5-50.0 ; 6-50.0 \\
7-33.9 ; 8-53.2 ; 9-30.9\end{array}$ & 46.9 \\
\hline Organizations & $\begin{array}{l}\text { *1-73.3; 2-62.5; 3-48.0; } \\
4-72.7 ; 5-70.0 ; 6-100.0 ; \\
7-55.0 ; 8-64.7 ; 9-73.3 ; \\
10-58.6 ; 11-50.0 ; 12-63.2 ; \\
13-73.3 ; 14-57.1 ; 15---; \\
16-80.0 ; 17-57.1 ; 18-75.0 ; \\
19-100.0 ; 20-81.8 ; 21-50.0 ; \\
22-55.0 ; 23-42.3 ; 24-73.9 ; \\
25-84.6 ; 26-47.8 ; 27-100.0 ; \\
28-43.5 ; 29-60.9 ; 30-61.5 ; \\
31-77.8\end{array}$ & 56.8 \\
\hline $\begin{array}{l}\text { Training } \\
\text { course }\end{array}$ & $1-65,3 ; 2-59.1 ; 3-68.4$ & 64.8 \\
\hline $\begin{array}{l}\text { Exposure } \\
\text { to concept }\end{array}$ & $1-82.1 ; 2-73.0$ & 76.9 \\
\hline
\end{tabular}

\section{CONCLUSION}

It seems as if the first research question posed in the introduction to this paper can be answered in quite a straightforward manner. The learning organization construct as measured by the Pedler, et al (1991) questionnaire seems to be uni-dimensional. It was not possible to replicate the view of the authors of the questionnaire that eleven underlying dimensions are measured and that these dimensions could be clustered into five groups. The results point to a one factor solution being acceptable. The second question - regarding the portability of the construct as measured by the instrument - can also be answered in the light of the results of the factor analysis and of the item analysis. All the items loaded .30 or higher on the one factor identified. All the items also had rtt-values of .30 or higher. It therefore seems as if the construct and the items used to measure it, should be regarded as entirely portable/applicable to at least the South African cultural and organizational environment. Studies in other cultural environments are probably to be undertaken in order to determine whether the results of this study can be generalized.

While some doubts still exist about the content validity of the instrument it seems clear that the Pedler et al. (1991) questionnaire must be regarded as measuring a uni-dimensional construct. The instrument has high internal consistency (reliability), as can be expected of a long scale.

The study indicated that the instrument probably has useful predictive/discriminatory ability. It could distinguish adequately between respondents from different economic sectors, working in different organizations, respondents with different levels of exposure to the construct, and in different fields of specialization or interest e.g. marketing and general management.

Future work should probably concentrate on the content validity of the instrument (i.e. does it measure the concept "learning organization" to its full extent) and on the predictive ability of the instrument e.g. can it predict (over the medium to long term), organizational effectiveness. A possible future study could be to determine the relationship, if any, between the effectiveness/success of managers (Luthans, 1988) and the degree to which the organization conform to the learning organization concept. The research question can therefore be: Do subordinates of effective managers see their (learning) organization different from subordinates of successful managers?

Another possible future study could be to determine the relationship, if any, between organizations's learn- 
ing and its strategy, and how it conforms to the learning organization concept. The research question can therefore be: Is learning the result of strategy, or strategy the result of learning in a learning organization?

Finally, the whole concept of the learning organization should be investigated further. Is the degree to which an organization is willing and able to learn not only one aspect of an organization's culture (or world view, or mental model of the world)? Are these so called "characteristics of a learning organization" not only facilitating factors in a learning culture? Are creating and improving learning capacity and learning capabilities in organizations, not more important to focus on in future than to "try and create a different type of learning organization" ?

\section{REFERENCES}

Anastasi, A. (1986), Evolving Concepts of Test Validation. Annual Review of Psychology.

Bahlman, T.(1990), The Learning Organization in a Turbulent Environment. Human Systems Management, 9, pp.249-256.

Banner, D.K.(1987), Of Paradigm, Transformation and Organisational Effectiveness. Leadership and Organisational Development Journal, 8(2), pp.17-28.

Braham, BJ. (1996), Creating a Learning Organisation, Kogan Page, London.

Buckler, B. (1996), A learning process model to achieve continuous improvement and innovation. The Learning Organisation, Vol. 3 No 3, pp. 31-39

Burgoyne, J., Pedler. M. and Boydell. T.(1994), Towards the Learning Company. McGraw-Hill, London.

De Geus, A.(1988), Planning as Learning. Harvard Business Review. March/April, pp.70-74.

DiBella, A.J. and Nevis, E.C.(1998), How organizations Learn. An Integrated Strategy for Building Learning Capability. Jossey-Bass, San Francisco.

DiBella, A.J.(2001), Learning Practices. Assessment and Action for Organisational Improvement. Prentice- Hall, New Jersey.

Donegan, J.(1990), The Learning Organisation: Lessons from British Petroleum. European Management Journal, September, 8(3).

Emory, C.W. and Cooper, D.R. (1991), Business Research Methods. Fourth Edition. Irwin, Boston.

Garratt, B. (1999), The learning organization 15 years on: some personal reflections. The Learning Organisation, Vol. 6, No. 5, pp. 202-206.

Garratt, B.(1987), The Learning Organization and the need for directors who think. Gower, Worcester, Great Britain.

Garvin, D.A.(1993), Building a Learning Organisation. Harvard Business Review, JulyAugust, pp 78-91.

Gharajedaghi, J. and Ackoff,R.L.(1984), Mechanisms, Organisms and Social Systems. Strategic Management Journal, 5, pp.289-300.

Gorelick, C. (2005), Organisational learning vs the learning organization: A conversation with a practitioner. The Learning Organsation, Vol. 12, No. 4, 
2005, pp. 38-388.

Guns, B. (1996), The Faster Leanring Organisation: Gain and Sustain the Competitive Advantage, JosseyBass, San Francisco, CA.

Hall, J.(1990), Bureaupathic management: New crisis in organizations? Human Resource Management, Yearbook.

Hawkins, P.(1991), The spiritual dimension of the learning organization. Management Education and Development, 22(3), pp.172-178.

http://www.efmd.org/html/home.asp

Jones, A.M. and Hendry, C.(1992), The Learning Organisation: A review of literature and practice. The HRD Partnership, London.

Kast, F.E. and Rosenzweig, J.E.(1985), Organization and Management. A Systems and Contingency Approach. Fourth Ed., McGraw-Hill, Johannesburg

Kay, R. and Bawden, R. (1996), Learning to be systemic: some reflections from a learning organization. The Learning Organisation, Vol. 3 No. 5, pp 18-25.

Kerlinger, F.N. (1986), Foundations of Behavioral Research. Third Edition. Holt, Rinehart and Winston, New York.

Kochan, T.A. and Useem, M.(Ed).(1992),

Transforming Organisations. Oxford University Press, Oxford.

Luthans, F.(1988), Successful vs effective real managers. The Academy of Management Executive, May, 11(2), pp.127-132.

Marquardt, MJ. And Kearsley, G. (1999), Building and Learning Organisations: A Systems Approach to Quantum Improvement and Global Success, McGraw-Hill, New York, NY.

Marsick, VJ and Watkins, KE. (1999), Looking again in the learning organization: A tool that can turn into a weapon. The Learning Organisation, Vol. 6, No. 5, pp. 207-11.

Mohrman, A.M.(Jr), Mohrman, S.A., Ledford,G.E.(Jr), Cummings,T.G., Lawler, E.E. III and Associates.(1989), Large Scale Organisational Change. Jossey-Bass Publishers, London.

Nevis, E.C., DiBella, A.J. and Gould, J.M.(1995), Understanding Organisations as Learning Systems. Sloan Management Review, Winter, pp. 73-85.

Pedler, M., Burgoyne, J. and Boydell, T.(1991), The Learning Company. A Strategy for Sustainable
Development. Mc Graw-Hill, London.

pp. 141-52.

Revans, R.W.(1982), The Orgins and Growth of Action Learning. Chartwell-Bratt.

Robinson, B.(1994), Voluntary Bodies as Learning Organsations. The Learning Organization, 1(3), pp.10-15.

SAS Institute Inc. (1988), SAS/STAT User's Guide. Relase 6.03 Eiditon. Cary, NC: SAS Institute Inc.

Schein, E.HS.(1993), How can Organizations Learn Faster? The Challenge of Entering the Green Room. Sloan Management Review. Winter, pp.85-92.

Senge, P.M.(1990), The Fifth Discipline. The Art and Practice of the Learning Organization.

Doubleday, New York

Stata, R.(1989), Organizational Learning - The Key to Management Innovation. Sloan Management Review, Spring, pp.63-74.

Stewart, D. (2001), Reinterpreting the learning organization. The Learning Organization, Vol. 8, No. 4,

Swieringa, J. and Wierdsma, A.(1992), Becoming a Learning Organization. Beyond the Learning Curve. Addison-Wesley Publishing Co., Amsterdam.

Teare, R. and Dealtry, R. (1998), Building and sustaining a learning organization, Vol, 5 No. 1, pp 4760 .

Walker, R.(1992), Rank Xerox. Management Revolution. Long Range Planning, 25(1), pp.9-21.

Watkins, K.E. and Golembeiwski, R.T.(1995), Rethinking Organization Development for the Learning Organization. The International Journal of Organizational Analysis, (3) 1, (January), pp.86-101.

Watkins, K.E. and Marsick, V.J.(1993), Sculpting the Learning Organization. Lessons in the Art and Science of Systematic Change. Jossey-Bass Publishers, San Francisco.

Yeo, R. (2003), Linking organizational learning to organizational performance: Singapore case studies. The Leadership and Organization Development Journal, Vol. 24, No. 2, pp.70-83. 